\title{
Bent needle technique as a rescue for bile duct puncture in endoscopic ultrasonography-guided intrahepatic biliary drainage
}

A 75-year-old woman with an ampullary cancer was admitted to our hospital for jaundice due to the obstruction of a biliary metal stent, which was placed 10 months earlier. Subsequently, she also underwent the placement of a noncovered duodenal metal stent from the third to the second part of the duodenum 1 month prior to admission. Accordingly, the distal end of the biliary metal stent

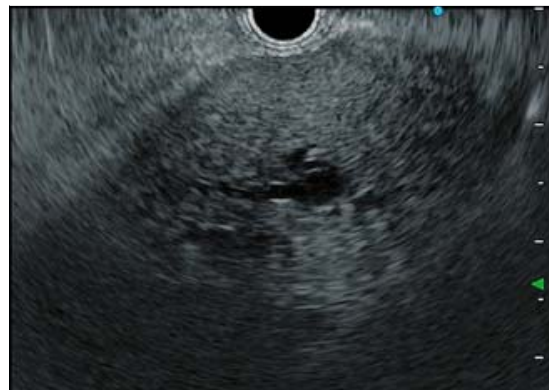

- Fig. 1 The site of needle insertion was limited because the visibility of the bile duct was hampered by deep attenuation in endoscopic ultrasound. was covered by the duodenal metal stent.

First, we tried to perform endoscopic retrograde cholangiopancreatography through the duodenal metal stent; however, this procedure failed. Therefore, the procedure was converted to endoscopic ultrasound-guided hepaticogastrostomy (EUS-HGS). However, the intrahepatic bile duct segments 2 (B2) and 3 were difficult to visualize from the stomach owing to deep ultrasound attenuation by fat, so that the site of needle insertion was limited ( $>$ Fig. 1, \Video 1 ). Bile duct puncture was attempted for B2 with a 19-gauge needle (Sono Tip Pro Control; Medi-Globe GmbH, Rosenheim, Germany), but this maneuver also failed because it was impossible to adjust the needle angle to the bile duct.

After removal of the needle, the needle was pushed completely out of the sheath and bent gently using the fingers to cre-

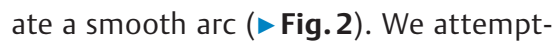
ed needle insertion again and finally succeeded in obtaining a cholangiogram
( $>$ Fig.3). Following insertion of a guidewire into the bile duct and dilation of the tract using a cautery catheter, we placed a covered metal stent ( $\triangleright$ Fig.4, - Video 1).

EUS-guided biliary drainage has been reported recently; however, endoscopists sometimes encounter difficult biliary access, especially when targeting the intrahepatic bile duct such as in EUS-HGS [1, 2]. Rigidity of the 19-gauge needle is the cause of the technical difficulty. In cases in which endoscopists cannot adjust the angle needed, needle bending can be a rescue technique for biliary access in EUS-HGS. This simple method may also be applied when regional or collateral vasculature cannot be excluded.

Endoscopy_UCTN_Code_TTT_1AS_2AD

\section{Competing interests}

None
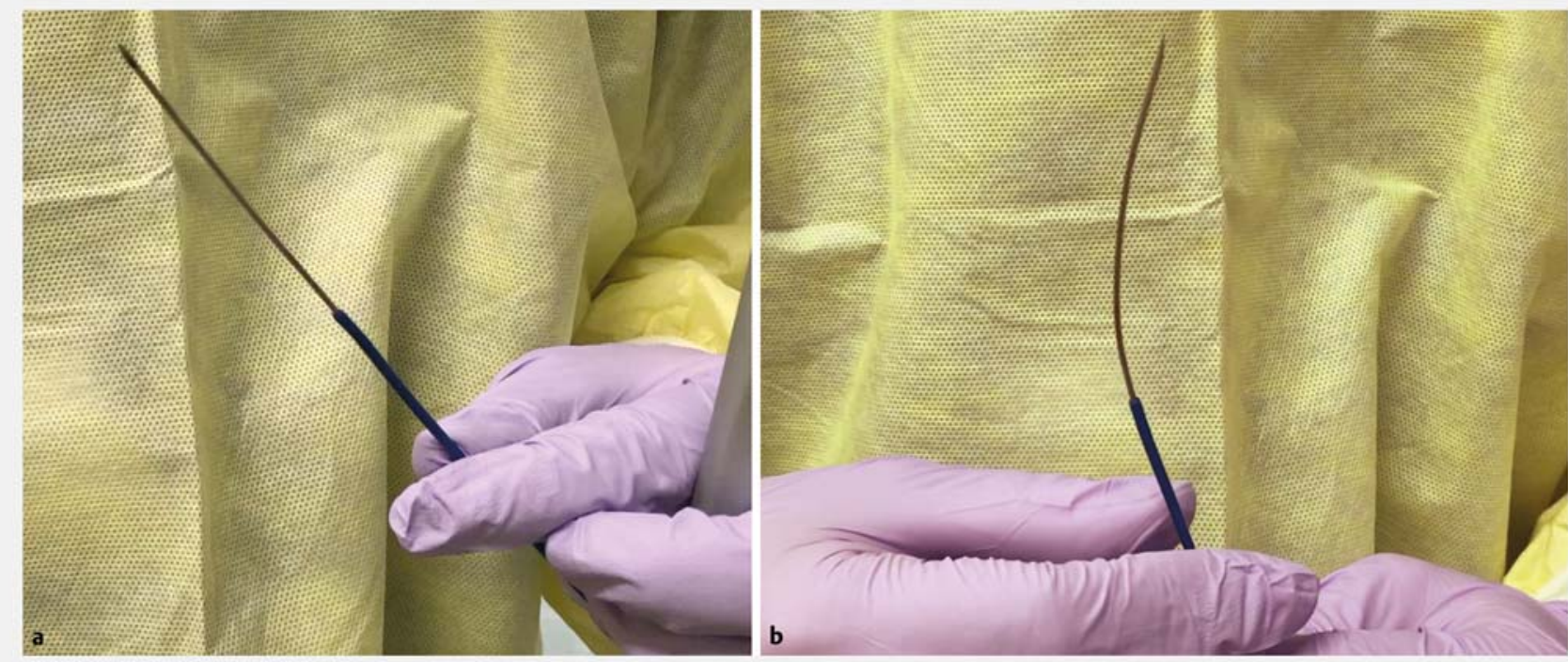

Fig. 2 Adjustment of the needle for biliary access. a The needle was pushed completely out of the sheath. $\mathbf{b}$ The needle was bent gently using the fingers. 


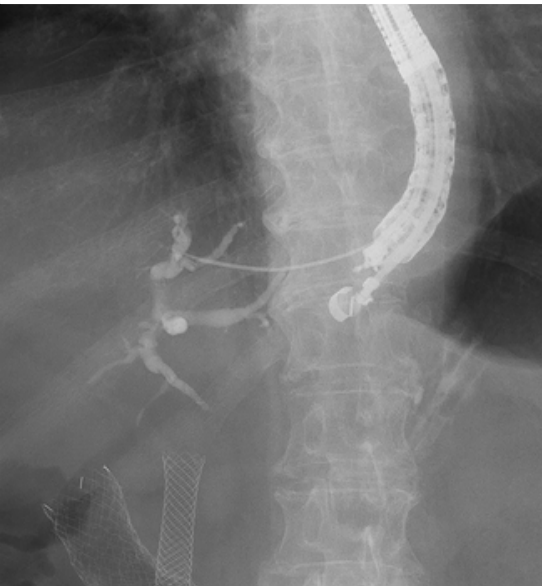

Fig. 3 The bile duct was punctured using a pre-bent needle and a cholangiogram was subsequently obtained.

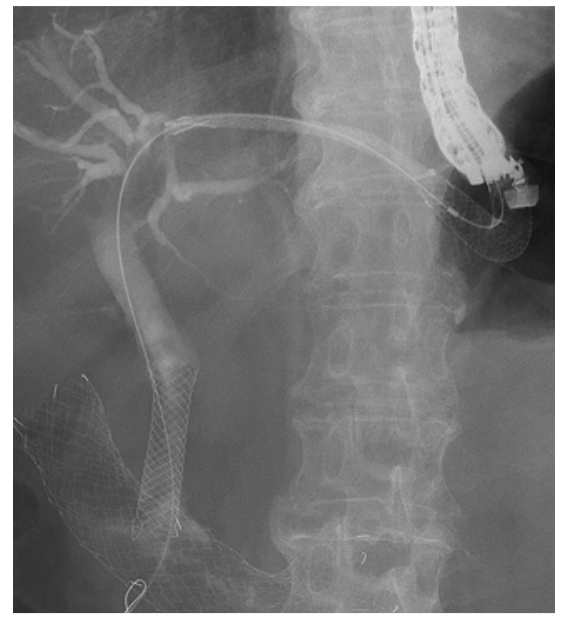

Fig. 4 A metal stent was inserted from B2 to the stomach.

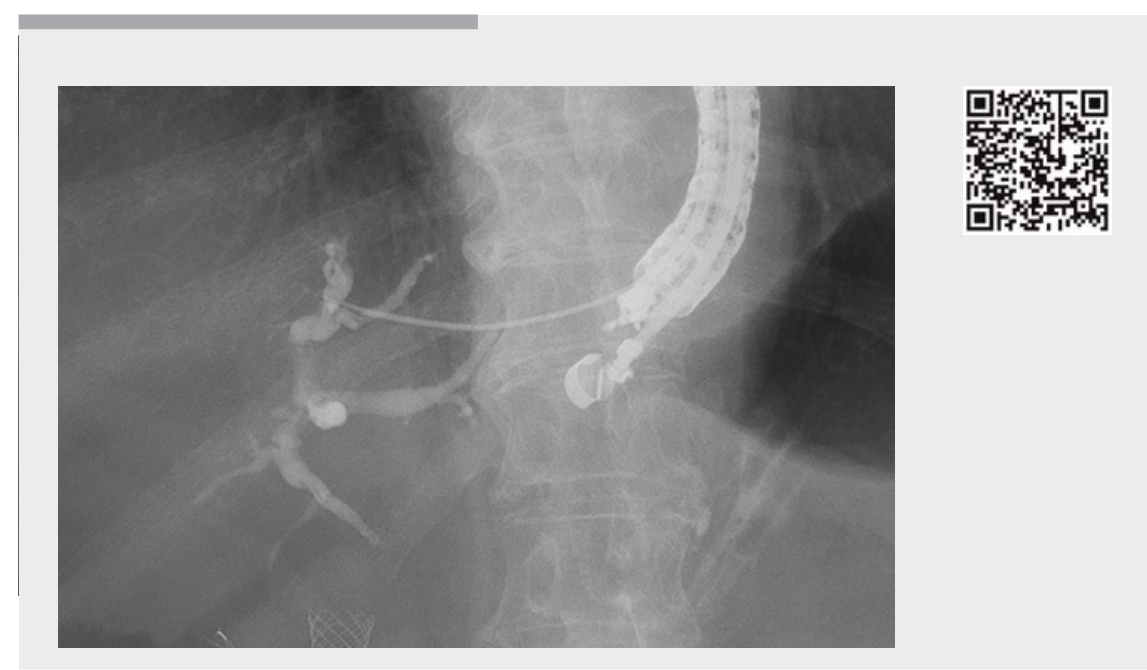

Video 1 Needle insertion during endoscopic ultrasound-guided hepaticogastrostomy was impossible because of difficulty in adjusting the angle needed in the patient with fatty liver; however, needle bending eventually allowed us to approach the bile duct.

\section{The authors}

Hirotoshi Ishiwatari ${ }^{1}$, Tatsunori Satoh ${ }^{1}$, Junya Sato $^{1}$, Shinya Fujie ${ }^{1}$, Junichi Kaneko ${ }^{1}$, Hiroyuki Matsubayashi $^{1,2}$, Hiroyuki Ono ${ }^{1}$

1 Division of Endoscopy, Shizuoka Cancer Center, Shizuoka, Japan

2 Familial Cancer Clinic, Shizuoka Cancer Center, Shizuoka, Japan

Corresponding author

\section{Hirotoshi Ishiwatari, MD, PhD}

Division of Endoscopy, Shizuoka Cancer Center, 1007 Shimonagakubo Nagaizumicho, Sunto-gun, Shizuoka, Japan Fax: +81-55-9895551 ishihiro481019@gmail.com

\section{References}

[1] Burmester E, Niehaus ], Leineweber T et al. EUS-cholangio-drainage of the bile duct: report of 4 cases. Gastrointest Endosc 2003; 57: $246-251$

[2] Giovannini M, Dotti M, Bories E et al. Hepaticogastrostomy by echo-endoscopy as a palliative treatment in a patient with metastatic biliary obstruction. Endoscopy 2003; 35: $1076-1078$

\section{Bibliography}

DOI https://doi.org/10.1055/a-0835-5843

Published online: 21.2.2019

Endoscopy 2019; 51: E103-E104

(c) Georg Thieme Verlag KG

Stuttgart · New York

ISSN 0013-726X

\section{ENDOSCOPY E-VIDEOS \\ https://eref.thieme.de/e-videos}

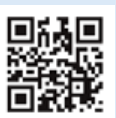

Endoscopy E-Videos is a free access online section, reporting on interesting cases and new techniques in gastroenterological endoscopy. All papers include a high quality video and all contributions are freely accessible online.

This section has its own submission website at

https://mc.manuscriptcentral.com/e-videos 